\title{
Timing of deciduous teeth emergence in Egyptian children
}

\author{
N.L. Soliman, ${ }^{1}$ M.A. El-Zainy, ${ }^{2}$ R.M. Hassan ${ }^{2}$ and R.M. Aly ${ }^{7}$
}

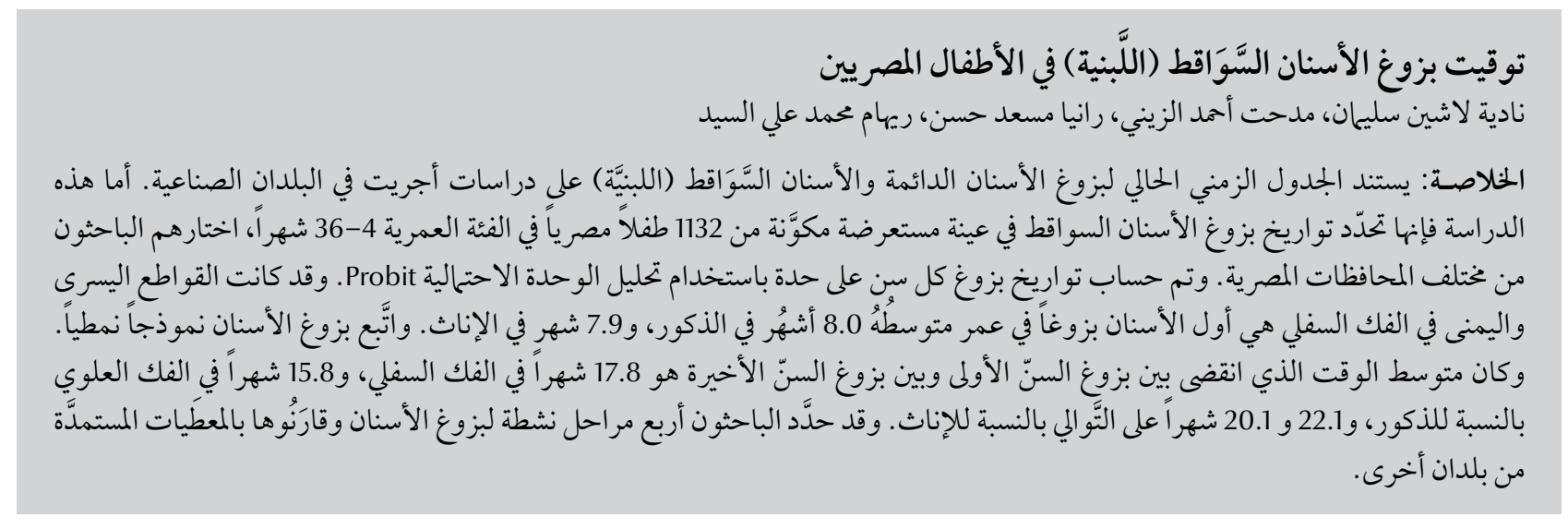

ABSTRACT The existing eruption schedules for permanent and deciduous dentition are based on studies in industrialized countries. This study determined the dates of emergence of deciduous teeth in a cross-sectional sample of 1132 Egyptian infants aged 4-36 months selected from different governorates of Egypt. The dates of emergence of individual teeth were calculated using Probit analysis. The mandibular left and right incisors were the earliest teeth to emerge at a mean of 8.0 months in boys and 7.9 months in girls. The sequence of eruption followed a typical pattern. The average time from emergence of the first tooth to the last tooth was 17.8 months in the mandible and 15.8 months in the maxilla for boys and 22.1 and 20.1 months respectively for girls. Four active phases of emergence were identified and compared with data from other countries.

\section{Calendrier d'éruption des dents temporaires chez les enfants égyptiens}

RÉSUMÉ Les calendriers actuels d'éruption des dents temporaires et permanentes sont fondés sur des études réalisées dans les pays industrialisés. La présente étude transversale a déterminé le calendrier d’éruption de ces dents dans un échantillon de 1132 enfants égyptiens âgés de 4 à 36 mois, sélectionnés dans différents gouvernorats d'Égypte. La chronologie de l'éruption des dents individuelles a été établie à l'aide de l'analyse par la méthode des probits. Les incisives droite et gauche de la mâchoire inférieure étaient les premières dents à apparaître à l'âge moyen de 8,0 mois chez les garçons et de 7,9 mois chez les filles. L'ordre de l'éruption dentaire suivait un modèle-type. Le délai moyen entre l'éruption de la première dent et celle de la dernière était de 17,8 mois pour le maxillaire inférieur et de 15,8 mois pour le maxillaire supérieur chez les garçons, et de 22,1 mois et 20,1 mois respectivement, pour les maxillaires inférieur et supérieur des filles. Quatre phases actives d'éruption ont été identifiées et comparées aux données des autres pays.

'Department of Basic Dental Science, National Research Centre, Cairo,Egypt (Correspondence to R.M. Aly: Riham.aly@hotmail.com). ${ }^{2}$ Department of Oral Biology, Faculty of Dentistry, Ain Shams University, Cairo, Egypt.

Received: 20/12/09; accepted: 03/03/10 


\section{Introduction}

Many efforts have been made to increase our knowledge about the eruption of deciduous teeth, not only the chronology and sequence of eruption but also the factors that may interfere with the eruptive process. Deciduous dentition usually emerges within the first 2.5 years of life. The timing and sequence of emergence of deciduous teeth differ to some extent between populations and geographic areas and even within seemingly homogenous groups; environmental factors exert some effect on the rate of emergence of dentition [1-7].

The existing eruption schedules for both permanent and deciduous dentition have been based on studies in industrialized countries. Since Egyptians differ from these populations racially, genetically and environmentally, such studies fail to provide relevant guidance on eruption times. Information on ages of eruption of deciduous teeth used in clinical and academic situations in Egypt is based on other populations [8]. The aim of this research was to determine the emergence dates of deciduous teeth, and their order and sequence, in a sample of Egyptian children.

\section{Methods}

\section{Sample}

A cross-sectional sample of 1132 Egyptian infants (565 girls and 567 boys) aged 4-36 months was selected throughout the year 2009. The sample was collected from randomly selected health centres affiliated to the Ministry of Health in 5 different governorates of Egypt in order to represent children from various socioeconomic strata and different geographic localities. Children visit these health centres regularly at pre-defined ages in order to receive their mandatory vaccinations. They are seen 5 times in the first year (at ages 2, 4, 6, 9 and 12 months), twice in the second year of life (at ages 18 and 24 months) and once yearly thereafter until age 5 years. At each visit the child's growth development and feeding patterns are determined in the paediatric clinic and recorded together with their vaccination dates in a file for each child. The recommendations in this clinic for infant feeding include exclusive breast-feeding in the first 6 months and continuing breastfeeding until 2 years of age with appropriate complementary food.

\section{Data collection}

Each infant in the sample was subjected to a full medical examination and only healthy normal subjects were included in the study sample. All children were given a dental examination. Oral examination was done using a dental mirror and probe in the presence of good illumination. The deciduous dental formula was recorded in each infant's examination sheet. Tooth eruption was defined as having occurred if any part of the crown had pierced the alveolar mucosa [8]. The examination was carried out by a dentist and 2 trained nurses who work in the health centre. The same equipment was used throughout the study and calibrated before use.

\section{Statistical analysis}

Statistical analysis was done using SPSS, version 17.5 software. The analysis included frequencies and descriptive statistics. Association between categorical variables was assessed using Pearson coefficient of correlation and analysis of variance. The independent sample Student $t$-test was used to assess the statistical significance of the differences in mean age of tooth emergence between males and females, and arch and side differences, at the $5 \%$ probability level. For calculating the mean age of emergence for each tooth in both sexes, the Probit model was adopted [9]. The Probit model assumes that:

$$
P(Y=1 / X=\mathcal{X})=\Phi\left(\mathcal{X}^{\prime} \beta\right)
$$

$P$ is probability and $\Phi$ is the Probit function; the cumulative distribution function of the standard distribution. $Y$ represents presence/absence of a tooth and $\chi$ is assumed to influence the outcome $Y$ that represents age in this case and is the age on the day of examination. Two methods were used to calculate the Probit values.

- Manual method [9-11]. For each tooth, the age was approximated to the nearest month and then all children in the sample of the same age were grouped. The percentage of children who had that tooth emerged in each age group was calculated. Probit function for the previously calculated percentage was calculated. Those Probit values were then plotted against the age to obtain the best fitting straight line (intercept, slope) using linear regression (Figure 1). From there the mean was calculated as (-intercept/slope), and the standard deviation (SD) as (1/slope).

- Computer software method (Gretl, version 1.8.2). This method implements a binary response regression model. The exact age on the date of examination was input and whether the tooth had emerged (1) or not (0). The Probit modelling function was executed, specifying the age as the independent variable and the emergence of the tooth as the dependent variable. The mean was calculated as (-coefficient of constant/coefficient of age) and the SD as $(1 /$ coefficient of age $)$.

\section{Results}

The mean times of emergence of deciduous teeth, for the 2 arches, for each side and for both sides combined, are presented in Table 1 for boys and Table 2 for girls. The average length of time taken from the emergence of the first tooth to the last tooth was 17.8 months in the mandible and 15.8 months in 


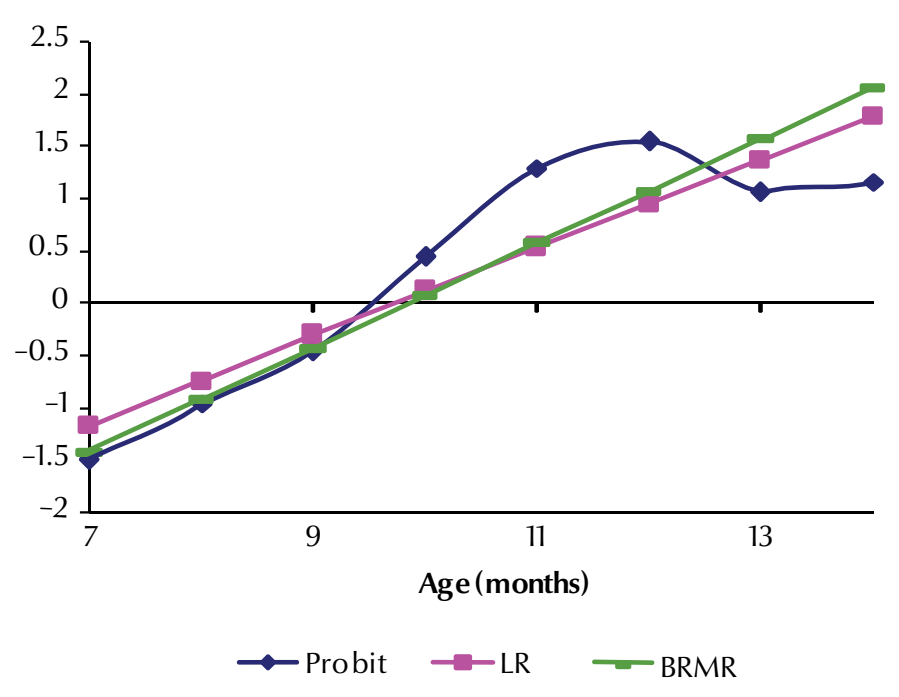

Figure 1 Example of probit analysis of maxillary left central incisor in boys (LR = linear regression; BRMR = binary response model regression)

the maxilla for boys and 22.1 and 20.1 months respectively for girls.

The mandibular left and right central incisors were the earliest set of teeth to emerge, at a mean age of 8.0 months and 7.9 months in boys and girls respectively. The maxillary central incisors emerged next (9.8 and 9.9 months), followed by the lateral incisors (12.0 and 13.2 months). Next to emerge were the maxillary (17.1 and 17.0 months) and mandibular (17.0 and 16.7 months) first molars, followed by the maxillary
(19.4 and 19.8 months) and the mandibular (20.3 and 19.6 months) canines and lastly the second molars, maxillary (25.4 and 28.9 months) and mandibular (25.6 and 28.1 months).

All maxillary teeth emerged earlier than the mandibular counterparts except for the lower central incisor (left and right respectively). The maxillary lateral, canine and second molar showed earlier emergence dates than in the mandible, but not significantly so. The mandibular central incisor and first deciduous molar emerged significantly earlier $(t$-test, $P<0.05)$.

Four active phases of emergence were identified. The first phase was the central and lateral incisors, which emerged within 8.8 months. There was a resting interval of about 3.2 months in the mandible and 3.5 months in the maxilla before the emergence of the first molars, which constituted the second active phase. All 4 molars were out in the oral cavity within a period of less than 1 month (with an average age of 16.4 months). The third active phase commenced with the emergence of the canines after a resting period of 2.3 months in the mandible and 2.1 months in the maxilla. The last phase was the emergence of the second molars, which occurred after a rest period of 5.0 months in the mandible and 6.0 months in the maxilla.

Generally in boys, the left side dentition showed significantly earlier emergence times, except for the maxillary second molar. In girls, the emergence times of the left and right side dentition were different from the boys but not significantly so. All mandibular right teeth emerged earlier than the mandibular left teeth. The maxillary left central incisor and the maxillary second molar were significantly ahead in their emergence

\begin{tabular}{|c|c|c|c|}
\hline \multirow[t]{3}{*}{ Tooth } & \multicolumn{3}{|c|}{ Age of emergence (months) } \\
\hline & Left side & Right side & Combined sides \\
\hline & Mean (SD) & Mean (SD) & Mean (SD) \\
\hline \multicolumn{4}{|l|}{ Maxilla } \\
\hline Central incisor & $9.9(2.0)$ & $9.7(2.0)$ & $9.8(2.0)$ \\
\hline Lateral incisor & $11.6(3.4)$ & $12.3(4.1)$ & $12.0(3.8)$ \\
\hline Canine & $19.5(3.8)$ & $19.3(3.8)$ & $19.4(3.8)$ \\
\hline 1st deciduous molar & $17.2(3.8)$ & $17.0(3.6)$ & $17.1(3.7)$ \\
\hline 2nd deciduous molar & $25.5(2.3)$ & $25.2(3.6)$ & $25.4(3.0)$ \\
\hline \multicolumn{4}{|l|}{ Mandible } \\
\hline Central incisor & $7.9(2.0)$ & $8.1(2.1)$ & $8.0(2.1)$ \\
\hline Lateral incisor & $12.7(3.7)$ & $13.2(4.2)$ & $13.0(4.0)$ \\
\hline Canine & $20.4(4.5)$ & $20.2(4.4)$ & $20.3(4.5)$ \\
\hline 1st deciduous molar & $17.0(4.4)$ & $17.0(4.2)$ & $17.0(4.3)$ \\
\hline 2nd deciduous molar & $25.4(3.6)$ & $25.7(3.6)$ & $25.6(3.6)$ \\
\hline
\end{tabular}

$S D=$ standard deviation . 


\begin{tabular}{|c|c|c|c|}
\hline \multirow[t]{3}{*}{ Tooth } & \multicolumn{3}{|c|}{ Age of emergence (months) } \\
\hline & Left side & Right side & Combined sides \\
\hline & Mean (SD) & Mean (SD) & Mean (SD) \\
\hline \multicolumn{4}{|l|}{ Maxilla } \\
\hline Central incisor & $9.8(4.8)$ & $10.0(4.8)$ & $9.9(4.8)$ \\
\hline Lateral incisor & $13.1(5.1)$ & $13.3(4.9)$ & $13.2(5.0)$ \\
\hline Canine & $20.0(4.3)$ & $19.9(4.3)$ & $19.8(4.3)$ \\
\hline 1st deciduous molar & $17.2(4.4)$ & $16.8(4.5)$ & $17.0(4.5)$ \\
\hline 2nd deciduous molar & $27.8(4.9)$ & $29.9(6.3)$ & $28.9(5.6)$ \\
\hline \multicolumn{4}{|l|}{ Mandible } \\
\hline Central incisor & $7.9(5.2)$ & $7.8(5.5)$ & $7.9(5.4)$ \\
\hline Lateral incisor & $13.6(6.1)$ & $12.7(4.5)$ & $13.2(5.3)$ \\
\hline Canine & $19.8(4.2)$ & $19.3(4.1)$ & $19.6(4.2)$ \\
\hline 1st deciduous molar & $16.6(4.7)$ & $16.8(4.6)$ & $16.7(4.7)$ \\
\hline 2nd deciduous molar & $29.9(6.3)$ & $26.3(5.0)$ & $28.1(5.7)$ \\
\hline
\end{tabular}

$S D=$ standard deviation.

times $(t$-test, $P<0.05)$, the rest of the teeth showed earlier emergence times in the right side, although the difference was not statistically significant [data not shown]. A comparison between side and arch emergence patterns of boys and girls revealed that maxillary left lateral incisors and left first molars showed significantly earlier emergence in boys $(t$-test, $P<0.05)$. In the right side girls' maxillary right lateral was significantly earlier $(t$-test, $P<0.05)$. When comparing between the upper and lower arches, in boys there was significantly earlier emergence of the lower left lateral incisor $(t$-test, $P<0.05)$ and in girls the right mandibular canines emerged earlier, but significantly so, than boys.

\section{Discussion}

The present study revealed that the sequence of emergence of deciduous teeth within each arch followed the typical trend, as presented in numerous research studies and textbooks. The normal time of emergence of deciduous teeth into the oral cavity occurs over a broad range of chronological ages. It is reported to begin by 4-10 months after birth and by about 30 months of age the 20 deciduous teeth are almost completed emerged [12-14]. The first tooth to emerge in our study was the mandibular central incisor, which emerged at 8.0 months, 2 months later than that reported by El Batran et al. in an earlier study on an Egyptian population [12].

In agreement with El Batran et al., however, the lateral incisor and canine showed earlier maxillary emergence, and the first deciduous molar showed earlier mandibular emergence [12]. In another Egyptian study by El-Hadary and El-Nesr all maxillary teeth showed earlier emergence dates when compared with their mandibular counterparts [15], but this was not consistent with our results nor with those of El Batran et al. [12].

Sex is reported to have either no effect on the timing of teeth emergence [16], a minimal but significant effect in favour of boys [17] or girls [8]. Tanguay et al. proposed that ethnic factors may mediate sex differences in tooth emergence, so that no single pattern can properly characterize sex differences in the pattern and timing of emergence worldwide [18]. Tanguay et al. also reported that the teeth of boys consistently emerged a month before those of girls, with one exception: the first deciduous molar. Holman and Jones reported that there was the little evidence for the hypothesis of ethnic-mediated sex differences in deciduous tooth emergence [16]. But they supported Demirijian and Levesque's idea of a developmental crossover in which males lead females in the anterior dentition and females lead males for the posterior dentition [5]. This pattern begins prenatally, with males advanced over females in dental development [19]. Holman et al. suggested that the pattern appears to follow a spatial gradient of tooth position, corresponding to sex differences arising early in dental development [16]. This overall developmental crossover pattern is consistent over many studies, even for many studies where sex differences were not found to be statistically significant [7]. In our study, this crossover pattern was not evident. In agreement with Tanguay et al.'s study on French-Canadian children [18] the present study showed that no significant sex difference could be detected except for certain teeth in which boys showed earlier emergence than girls. The lower first deciduous molar was the only tooth that emerged significantly earlier in girls. Similar data were reported by El Batran et al. in Egyptian children [12]. 

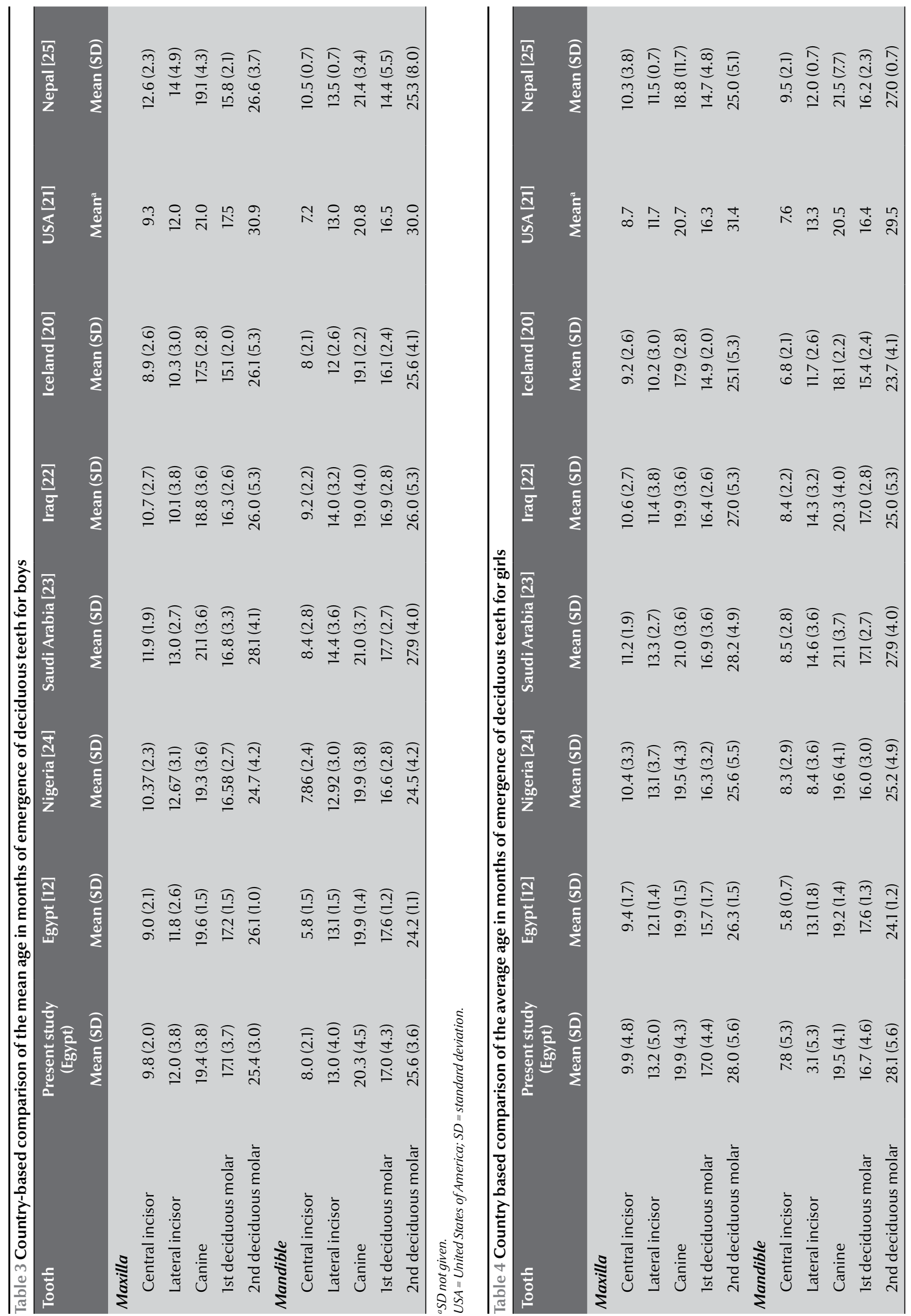


\begin{tabular}{|c|c|c|c|c|c|c|c|c|}
\hline \multirow[t]{3}{*}{ Phases } & \multicolumn{8}{|c|}{ Mean interval (months) } \\
\hline & \multicolumn{2}{|c|}{ Egypt (present study) } & \multicolumn{2}{|c|}{ Saudi Arabia [23] } & \multicolumn{2}{|c|}{ Nigeria [24] } & \multicolumn{2}{|c|}{ Nepal [25] } \\
\hline & Mandible & Maxilla & Mandible & Maxilla & Mandible & Maxilla & Mandible & Maxilla \\
\hline $1-2$ & 3.2 & 3.5 & 2.6 & 3.7 & 3.1 & 3.6 & 2 & 2 \\
\hline $2-3$ & 2.3 & 2.1 & 3.9 & 4.2 & 3.4 & 2.9 & 6 & 4 \\
\hline $3-4$ & 5.0 & 5.9 & 6.9 & 7.1 & 4.9 & 5.4 & 4 & 6 \\
\hline
\end{tabular}

Tables 3 and 4 compare the results of the present study with those of previous studies on an Egyptian population [12] together with the timing the emergence of primary teeth of children from Iceland [20], USA [21], Iraq [22], Saudi Arabia [23], Nigeria [24] and Nepal [25]. The sequence of eruption was identical in all the countries. There were some differences, however, in the timing of eruptions. The first teeth to erupt were the mandibular central incisors. The timing of eruption of these teeth in Egyptian children was comparable to that of Saudi Arabians and
Nigerians, but earlier than in Iraqis and Nepalis. The Americans showed the earliest dates in relation to other countries. Nepalese children were slightly delayed in the eruption of incisor teeth compared with all other groups. As for the Egyptian children, the timing of the mandibular central incisors was 2.2 months later than the previous study on Egyptian children.

The intervals between the phases of teeth emergence in the mandible and the maxilla identified in different countries and the present study are shown in Table 5. Egyptian children showed a shorter interval of time between phases 2-3 than other countries, while the interval for phases $1-2$ and $3-4$ were very similar to the Nigerian population and shorter than for the Saudi children.

In conclusion, the current findings will provide paediatric dentists in Egypt with contemporary tooth emergence ages derived from an Egyptian population, which can be used for assessing dental growth and development in this country.

\section{References}

1. Infante PF, Owen GM. Relation of chronology of deciduous tooth emergence to height, weight and head circumference in children. Archives of Oral Biology, 1973, 18:1411-1147.

2. Trupkin DP. Eruption patterns of the first primary tooth in infants who were underweight at birth. ASDC Journal of Dentistry for Children, 1974, 41:279-282.

3. Delgado $\mathrm{H}$ et al. Nutritional status and the timing of deciduous tooth eruption. American Journal of Clinical Nutrition, 1975, 28:216-224.

4. Demirijian A, Falkner F, Tanner JM. Dentition in human growth, Volume 2, Postnatal growth. New York, Plenum Press, 1986.

5. Demirjian A, Levesque GY. Sexual differences in dental development and prediction of emergence. Journal of Dental Research, 1980, 59:1110-1122.

6. Fadavi $\mathrm{S}$ et al. Eruption pattern in the primary dentition of premature low-birth weight children. Journal of Dentistry for Children, 1992, 59:120-122.

7. Saleemi M et al. Early child health in Lahore, Pakistan: XIII. Primary teeth emergence. Acta Paediatrica Supplement, 1994, 82(Suppl. 390):159-167.

8. Nofely A et al. Decidiuos tooth emergence in relation to somatic growth and nutritional status in a Middle Eastern population. Egyptian Dental Journal, 2002, 48:1201-1206.

9. Finney DJ. Probit analysis, 2nd ed. Cambridge, Cambridge University Press, 1952:236-245.

10. Gates RE. Eruption of permanent teeth of New South Wales school children. II. Sequence of eruption and commencement and completion of the dentition. Australian Dental Journal, 1964, 9:380-386.
11. Hayes RL, Mantel N. Procedures for computing the mean age of eruption of deciduous teeth. Journal of Dental Research, 1958, 38:938-947.

12. El-Batran MM, Abou-Zeid AW, Soliman NL. Dates of emergence of deciduous teeth in a sample of Egyptian children. Egyptian Dental Journal, 2002, 48:33-40.

13. Psoter WJ et al. Median ages of eruption of the primary teeth in white and hispanic children from Arizona. Pediatric Dentistry, 2003, 25:257-261.

14. Sahin $\mathrm{F}$ et al. Factors affecting the timing of teething in healthy Turkish infants: a prospective cohort study. International Journal of Paediatric Dentistry, 2009, 18:262-266.

15. El-Hadary MS, El-Nesr NM. Eruption of the deciduous teeth in two different socioeconomic groups. Alexandria Dental Journal, 1976, 1:61-78.

16. Holman DJ, Jones RE. Longitudinal analysis of deciduous tooth emergence: IV. Covariate effects in Japanese children. American Journal of Physical Anthropology, 2005, 126(3):352358.

17. Choi NK, Yang KH. A study on the eruption timing of primary teeth in Korean children. ASDC Journal of Dentistry for Children, 2001, 68(4):228, 244-249.

18. Tanguay R, Buschang PH, Demirjian A. Sexual dimorphism in the emergence of deciduous teeth: its relationship with growth components in height. American Journal of Physical Anthropology, 1986, 69(4):511-515.

19. Burdi AR, Garn SM, Miller RL. Development advancement of the male in the first trimester. Journal of Dental Research, 1970, 49:889. 
20. Magnusson TE. Emergence of primary teeth and onset of dental stages in Icelandic children. Community Dentistry and Oral Epidemiology, 1982, 10:91-97.

21. Nanda RS. Eruption in human teeth. American Journal of Orthodontics, 1960, 46:363-378.

22. Baghdady VS, Ghose LJ. Eruption time of primary teeth in Iraqi children. Community Dentistry and Oral Epidemiology, 1981, 9:245-246.
23. Al-Jasser NM, Bello LL. Time of eruption of primary dentition in Saudi children. Journal of Contemporary Dental Practice, 2003, 4:65-75.

24. Folayan $\mathrm{M}$ et al. The timing of eruption of the primary dentition in Nigerian children. American Journal of Physical Anthropology, 2007, 134:443-448.

25. Gupta A et al. Emergence of primary teeth in children of Sunsari district of eastern Nepal. McGill Journal of Medicine, 2007, 10:11-15.

\section{Milk fluoridation for the prevention of dental caries}

Around the globe, dental caries is a public health problem and the disease burden is particularly high among underprivileged groups. In several low-income countries, the WHO anticipates that the incidence of dental caries will increase as a result of growing consumption of sugars and inadequate exposure to fluorides.

The good news is that dental caries is preventable through the effective use of fluoride. WHO emphasizes the importance of automatic administration of fluoride as part of public health programmes. Substantial research has provided evidence of the effectiveness of milk fluoridation in the prevention of dental caries. As milk fluoridation mostly targets the child population, such schemes have been established within the context of school health programmes and programmes for healthy diet and nutrition. Milk fluoridation for the prevention of dental caries describes the justification of milk fluoridation as an effective public health measure and experiences from community health programmes are highlighted.

Further information about this and other WHO publications is available at: http://www.who.int/publications/en/ 